Białoruski Uniwersytet Panstwowy informatyki i radioelektroniki, Mińsk https://orcid.org/0000-0002-1157-4806

\title{
Готическая эстетика в рассказе Анатолия Козлова «I тады я памёр...»
}

Готическая литература с момента своего возникновения проявляла большой интерес к природе человеческого страха, его воздействию на психику, на душевные и духовные сферы деятельности личности. Человек обладает безграничным воображением, и именно оно способно создавать самые фантастические миры, живущие по своим законам.

Главной эстетической категорией в готическом произведении становится ужасное. Страх, как правило, вызывает чувства растерянности и потерянности, которые могут граничить с безысходностью. В Средние века категория ужасного являлась важной этической доминантой, и неизбежность Страшного суда и кары за грехи вызывали в человеке благоговейный трепет. В кризисные эпохи, когда прежняя картина мира рушится, а новая еще не сформирована, именно категория ужасного выходит на первый план.

Смерть, как известно, выступает фундаментальной движущей силой человечества, она всегда окутана пеленой таинственности и мистики, поэтому тема смерти является основополагающей для готической литературы. Непредсказуемость и неизбежность выносят смерть за пределы человеческого понимания, а все, что скрыто от восприятия, вызывает интерес и попытки постичь неведомое. Мировые религии трактуют смерть как божественную кару за грехи либо как блаженный дар на вечную жизнь. Готическая литература принимает сам факт неотвратимости смерти и существования другой жизни. Следует отметить, что в готике граница между жизнью и смертью подвижна 
и проходима в обе стороны. Готическая эстетика связана с интересом к смерти, с повышенным вниманием к картинам упадка, запустения и мрака.

В трактовке ужасного писатели опираются на трактат Эдмунда Бёрка «Философское исследование о происхождении наших идей возвышенного и прекрасного» (1756). Категории ужасного и возвышенного у философа взаимосвязаны. Э. Бёрк пишет:

...если боль и страх смягчены до такой степени, что фактически не причиняют вреда; если боль не переходит в насилие, а страх не вызван угрозой немедленной гибели человека; то, поскольку эти возбуждения освобождают части и органы тела, как тонкие, так и грубые, от опасного и беспокойного бремени, они способны вызывать восторг; не удовольствие, а своего рода восторженный ужас, своего рода спокойствие, окрашенное страхом; а поскольку оно относится к самосохранению, то является одним из самых сильных из всех аффектов. Его объект - возвышенное ${ }^{1}$

Ужасное и влечет, и отталкивает одновременно, однако философ подчеркивает, что боль и страх только тогда вызывают восторг, когда не несут реальной угрозы. Таким образом, человек, находясь в полной безопасности от описываемого ужаса, испытывает своеобразный катарсис. Изображение ужасного, как полагает Э. Бёрк, не должно быть слишком явным, чтобы не нарушить психологический эффект страха. Для достижения максимального психологического напряжения ужас должен быть окутан тайной. Английская писательница Анна Радклиф в эссе «О сверхъестественном в поэзии» выделяет две категории страха - horror и terror, при этом только один из них, как полагает писательница, способен вызвать эстетическое переживание, и это terror. Он вызван деятельностью души, это предчувствие ужаса, которое порождает напряженная атмосфера ожидания, она одновременно возбуждает чувства мрачности или меланхолии, или торжественности и ведет $\kappa$ вьсшей степени любопьтства и волнующему тре$n e m y^{2}$. Именно terror позволяет говорить об эстетической стороне переживания. Horror - это ужас, вызванный страшными, отвратительными предметами и явлениями.

1 Э. Бёрк, Философское исследование о происхождении наших идей возвышенного и прекрасного, Москва 1979, с. 159.

2 A. Radcliffe, On the supernatural in poetry, "New Monthly Magazine" 1826, Vol. 16, № 1, p. 148 . 
В зависимости от эффекта и степени воздействия страха литературоведы выделяют два направления в готической традиции - френетическое (М.Г. Льюис, У. Бекфорд, Э.А. По, Г.Ф. Лавкрафт) и сентиментальное (А. Радклиф, Э. Бронте, Н. Готорн, Г. Джеймс). Эти направления разными художественными средствами реализуют задачу эмоционального воздействия на читателя. Сентиментальной готике свойственна атмосфера ожидания и чувствительности, которая должна заставить воображение читателя работать и получать наслаждение от постепенного нагнетания страха. Френетическая готика отвергает сентиментальность и обращается к дикому и необузданному проявлению ужаса, чтобы повергнуть читателя в шок. Инструментом [френетической готики - E.T.] бьл не столько terror - страх, согласно Бёрку и Радклиф, неразлучный с чувством наслаждения, пробуждающий деятельность души и мысль о величественном, сколько horror, ux уничтожающий ${ }^{3}$ - отмечает В.Э. Вацуро. Таким образом, terror подразумевает постепенное нагнетание страха, напряженное ожидание чего-то ужасного, horror же стремится воздействовать на читателя через шокирующие сцены насилия и смерти.

Теоретики считают, что готика обладает функцией катарсиса, ведь вымышленные ужасы помогают справиться с реальными. Произведение литературы ужасов воздействует на глубины человеческого подсознания, затрагивает источник его страхов и самых примитивных суеверий. Страх, как известно, не признает ни социального положения человека, ни уровня его интеллекта. Готическое произведение обнажает тайные читательские тревоги, в которых он боится признаться, но которые все же существуют.

Готика концентрируется на темной стороне человеческой психики, на тех запретах и табу, которые присущи любому индивиду. Смерть, как известно, выступает фундаментальной движущей силой человечества, она всегда окутана пеленой таинственности и мистики, поэтому тема смерти является основополагающей для готической литературы. Во все времена человека интересовал вопрос конечности жизни и существования загробного царства, о чем свидетельствуют мифы и легенды стран и народов мира. Таким образом, у человека возникает идея своего мира, видимого и осязаемого, и чужого, скрытого от глаз и недоступного разуму, такое противопоставление ведет к появлению оппозиции Я-Другой. Столкновение с Другим, Чужим побуждает

3 В. Э. Вацуро, Готический роман в России, Москва 2002, с. 160. 
к анализу неведомых прежде чувств, а также может вызывать психологическую трансформацию личности. Проблема столкновения с Другим поднималась философами-экзистенциалистами. Ж.-П. Сартр и Э. Левинас пытались дать ответ на вопрос, кем является Другой, насколько он ограничивает свободу личности и как сосуществуют собственное Я и Другой. Экзистенциалисты убеждены, что существование Другого - это необходимое условие Бытия, присутствие Другого наполняет смыслом существование человека.

Место действия в готическом произведении способствует созданию гнетущей атмосферы страха. В ранних готических романах основным местом действия выступал замок. По мере эволюции жанра события стали разворачиваться в монастырях, на кладбищах, в фамильных особняках, соборах, домах и квартирах. Неизменным остается лишь тот факт, что герой находится во власти сверхъестественных сил, лицом к лицу со своей судьбой в замкнутом пространстве.

Интерес белорусских писателей к необъяснимым явлениям всегда присутствовал в национальной литературе, не ослабевал он и в ХХ веке. Повышенное внимание к инфернальному и мистическому проявлял Максим Горецкий. Писатель тонко передавал атмосферу загадочного и таинственного в рассказах «Патаёмнае», «Цёмны лес», «Страхаццё», «Што яно?», «Трасца». Писатель, опираясь на традиции Н. Гоголя, Ф. Достоевского, Л. Толстого, Я. Барщевского, открывал читателю новую страницу духовной жизни белорусского народа, сокровища его фольклорного наследия, жизненную философскую мудрость. Богатое наследие белорусов - легенды, сказки - является тем «патаёмным», что притягивает своей страшной таинственностью и необъяснимой загадочностью.

Интерес к готической традиции проявился и в творчестве В. Короткевича (повесть «Дикая охота короля Стаха»). Древняя легенда о дикой охоте позволила писателю погрузиться в неизведанное прошлое с его мрачными тайнами и непредсказуемыми нравами. Готический прием, когда прошлое с помощью фольклорных мотивов и образов (родовое проклятие и легенды о дикой охоте) вторглось в настоящее, стал неотъемлемой частью повести и существенно повлиял на психику героев и их будущее. В повести В. Короткевича широко использованы такие элементы готического романа, как родовое проклятие, готический замок среди серых болот, его таинственная атмосфера, привидения в имении, счастливый финал в конце произведения. Использованный писателем детективный элемент усиливает напряжение и чувство тревоги в произведении. Следуя традициям «сентимен- 
тальной готики» (А. Радклиф), которой свойственна атмосфера напряженного ожидания, сверхъестественное у В. Короткевича получает рациональное объяснение: читателю открываются загадочные тайны дикой охоты.

Интерес к готическому не исчезает в современной белорусской литературе и искусстве. Общественно-политические потрясения конца ХХ века (политическая оттепель, взрыв на ЧАЭС, распад СССР, подписание Декларации о государственном суверенитете БССР, закрепление за белорусским языком статуса государственного) глубоко затронули судьбы миллионов людей. Общество тяжело переживало утрату тех устоев, которые формировались на протяжении многих десятилетий. Магло здациа, што тут, у канцы стагоддзя $i$ тылсячагоддзя, умяшаліся нейкія містьиныля сільи ${ }^{4}$ - отмечает исследователь С.А. Андраюк. Многие белорусские писатели откликнулись на перемены в общественной жизни, поэтому литературный процесс конца 1980-х - начала 1990-х очень богат и разнообразен как в тематическом плане, так и в средствах художественной выразительности. Писатели обращались к новым темам, сюжетам, пытались глубоко осмысливать жизнь простого человека и его роль в быстро меняющемся мире.

На первый план в национальной литературе этого периода часто выходит фантастическое, таинственное («Лялька» (1993) Николая Костюкевича, «І тады я памёр» (1993), «Незламаная свечка» (2000) Анатолия Козлова). И как справедливо отмечает С. Андраюк, у творчасиі пісьменнікаў зусім рэалістьчнага светаўспрымання назіраециа з'яўленне элементаў фантастьчнага: сюжэтай, сітуацьй, калізій,

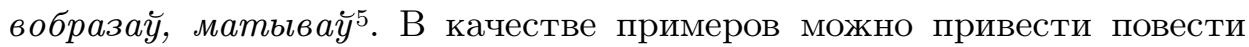
Алеся Адамовича «Пастораль» (1989), Янки Сипакова «Блуканні па іншасвеце» (1994), Виктара Казько «Прахожы» (1995). Следует отметить, что белорусские писатели не перенимают всю систему художественных возможностей готического стиля, а используют лишь некоторые элементы готической поэтики и отдельные образы. Белорусский литературовед Р. Козловский отмечает, что фантастычны элемент, які недасведчанаму чьтачу кідаециа ў вочь ў першую чаргу, адыходзіиь на другі план, адьгрььваючь ролю эмачьйна-экспрэсіўнага фону

4 С.А. Андраюк, Літаратура перьляду 1986-2000 гадоў. Проза, [у:] Гісторызя берарускай літаратуры ХХ стагоддзя: У 4 m. 1986-2000, Мінск 2003, т. 4, кн. 2, с. 8.

5 Там же, с. 31 . 
падзей ${ }^{6}$. На первый план выходят психология героев, их образ мышления и мотивация поступков.

Смелым экспериментатором, использовавшим новое, нетрадиционное в своих произведениях конца XX века, можно назвать Анатолия Козлова. Философские рассуждения, присутствие фольклорных мотивов, склонность к мистификации становятся отличительными чертами прозы писателя. Мистическими мотивами насыщена повесть «Незламаная свечка». Эти мотивы присутствуют и в повести «Дзеці ночы», но здесь они не являются центральными, а служат лишь фоном для показа животрепещущих проблем молодого поколения.

Рассказ «І тады я памёр...» - это глубокое философское рассуждение о смерти, смысле жизни, о предназначении человека и жизни после смерти. Рассказ построен в форме мозаики: в нем шесть небольших зарисовок, объединенных темой неминуемости смерти. Каждая из зарисовок представляет собой отдельный жизненный фрагмент, неизбежно заканчивающийся смертью. Герой первого фрагмента - всецело поглощенный работой режиссер. Он встречает на улице незнакомца, который является его проводником в другой мир и заставляет режиссера задуматься о том, что занятый делами человек теряет связь с тем, что действительно значимо, - с близкими, семьей. Человек может сколько угодно смотреть на мир, но понять его до конца не в силах: Бачыць можна шмат чаго, а вось убачьиь усё - немагчыма, тьм больш зразумець. (...) Ачарсцвела твая душа, хлопча. Кажу табе як старонні назіральнік, пасрэднік.

Незнакомец в произведении выполняет роль готического "злодея", но в отличии от готических романов незнакомец-чужак у А. Козлова не играет активной роли. Путешествие режиссера с незнакомцем заканчивается кульминационным моментом, когда герой прибывает к воротам, где его охватывает чувство страха и потерянности:

I вось тут упершыню з пачатку гэтай няпростай гісторыі мне стала страшна. Адчуў на сабе той самы жах, калі валасы становяцца на дыбкі, а скуру пакрываюць гусіныя пупры. Але гэтае адчуванне жаху доўжылася нейкую долю хвіліны. Адняўшы ад вачэй рукі, я не ўбачыў побач з сабой чалавека, з якім ехаў. Пусты салон. А да ірэальнай брамы заставаліся лічаныя метры. Глыбокі ўдых, і «жыгулёнак» імчыць у абсалютнай цемры.

6 Р. Казлоўскі, Готыка ў творчасці Міколь Касцюкевіча (на прыкладзе апавядання «Лялька»), "На Нёманскай хвалі" 2014, № 4, с. 179.

7 А. Казлоӵ, I тады я памёр... [online], https://knihi.com/Anatol_Kazlou/I_tady_ja_ pamior.html\#1, [доступ: 26.01.2020]. 
У жываце нешта скруціла, падпёрла пад грудзі, і я не магу дыхаць, цела пацее, закладае вушы, здаецца, нехта нябачны пляскатымі і халоднымі пальцамі ўціскае вочы, якія во-во выпырснуць праз патыліцу, у вушах гудзе, быццам у тапельца, які праз міг, адзін усплёск пераступіць мяжу жыцця. Няўжо гэта і ёсць смерць? Трэба сашчапіць на грудзях рукі. Вось і...8

Второй фрагмент - зарисовка из прожитой жизни героя, которая теперь снова всплыла в его подсознании. С чувством вины он встречает мать и отца. Отец говорит, что колесо жизни никогда не останавливается, смерть не есть конец, она - всего лишь начало новой жизни: Не бойся, ты вернешся ў сонечны свет другім зямным жыциём, не помнячь падрабязнасией свайго папярэдняга вопьтуу, а можа, $i$ будзеш помніць. Не бойся таго, што завециа смерию. Яе не існуе. А вечнасць - невыляральная, без пачатку і каниа 9 . Человек, постигший эту истину, по утверждению отца, по-настоящему богат.

Третий фрагмент - путешествие героя в царство мертвых в ковчеге, который больше напоминает плацкартный вагон. Пограничникам, которых герой встречает в поезде, его попутчица отдает часы. Часы - символ земной жизни и конкретного времени, этого нет там, куда едут герои. Тетка Хая, попутчица героя, рассуждает о жизни отдельного человека и всего народа так: оправдана ли гибель одного ради спасения многих. Она сравнивает себя с Каиафой - библейским героем, первосвященником Иудеи, который решал судьбу Иисуса Христа: Лепш няхай загіне адзін чалавек, чьм увесь народ10. Но герой А. Козлова отрицает данный принцип, он грубоко убежден в ценности каждой личности: Ахвяруючь адным чалавекам, мы ахвяруем народам. Бо адзінкі ў суме складаюиь народ. Ні для кога не бачна той мяжы, калі з адзінак, дзесяткаў, сочень і тысяч складваеииа народ. Вы ахвяруече мною, я вамі $i . .$. Не, не! Виз з жахлівага, крыввавага роду! Народ жа гэта кожнь! 11

Герои этого фрагмента, опираясь на теорию 3. Фрейда, рассуждают о бесчеловечности человека исходя из того, что его животная натура является источником бесчеловечности, но человек не есть простое животное, его поведение детерминировано моралью и культурой.

8 А. Казлоў, I тады я памёр... [online], https://knihi.com/Anatol_Kazlou/I_tady_ja_ pamior.html\#1, [доступ: 26.01.2020].

9 Там же.

10 Там же.

11 Там же. 
Тетка Хая А. Козлова приходит к выводу, что бесчалавечнае иесна пераплецена з чалавечнасию ${ }^{12}$. Как Добро не возможно без Зла, так и человечное не возможно без бесчеловечности.

Герои фрагмента вместе ищут дорогу в Рай, но не находят ее. Повествование каждого фрагмента имеет открытый финал. Новый эпизод обозначает новый виток жизни и новое перерождение. А. Козлов использует и мифологические образы, сюжеты, так, герой одного из фрагментов Сымон превращен ведьмой Марой в оборотня. За мифологическими образами скрыт глубокий смысл человеческой жизни: герой в волчьем обличии вынужден скитаться по свету, он чужой и для волков, и для человека. Таким образом писатель трактует тему одиночества личности. Повествование фрагмента снова обрывается фразой « тады я памёр...».

Новый эпизод переносит читателя в городскую квартиру, тема одиночества лейтмотивом звучит и здесь. На фоне веселья собутыльников воспоминания героя о войне насыщены еще большим трагизмом. Он размышляет: имеет ли значение протест одной личности против войны, голода, несправедливости? Ответ очевиден - не имеет, повествование вновь обрывается смертью героя: I мяне зноў не стала ${ }^{13}$.

Очередной случай переносит героя в больницу, где врачи спасают ему жизнь после падения в канализационный колодец. Яркая художественная деталь канализаиионный колодеи становится символом падения-разложения всего человечества. Автор задается вопросом, способно ли человечество выбраться из глубокой темноты колодца с нечистотами? Не известно.

Таким образом, А. Козлов стремится вызвать у читателя не просто страх, а показать глубину переживаний личности, ее антропологическое одиночество, и готические элементы произведения являются тем важным акцентом, который помогает писателю актуализировать свое мировидение. Поэтика рассказа предполагает, что каждый раз, выходя на новый виток жизни, человек по-прежнему ищет ответы на вечные вопросы. В произведении доминирует жалобная мелодия, и каждый новый куплет ее - это очередное испытание человека и его трагическая гибель. Мысль писателя, что человек во все времена постигает тайны-загадки своего Я, но в кризисные эпохи трагизм мировосприятия

\footnotetext{
12 Там же.

13 А. Казлоў, I тады я памёр... [online], https://knihi.com/Anatol_Kazlou/I_tady_ja_ pamior.html\#1, [доступ: 26.01.2020].
} 
человеческой личности звучит особенно отчетливо. Поиски своей сущности, смысла жизни и смерти ярко воплощены во всех шести фрагментах рассказа «I тады я памёр...», а присутствие библейских, мифологических персонажей, отсылки к философским трудам известных людей убеждают читателя в том, что проблема человеческой личности являются неисчерпаемой.

\section{I T E R A T UR A}

Andraûk S.A., Litaratura peryâdu 1986-2000 gadou. Proza, [u:] Gistoryâ beraruskaj litaratury XX stagoddzâ: U 4 t. T. 4. Kn. 2. 1986-2000, Mìnsk 2003 [Андраюк С.А., Лimapamyра перыляду 1986-2000 гадоў. Проза, [у:] Гісторьия берарускай літаратуры XX стагоддзя: У 4 т. Т. 4. Кн. 2. 1986-2000, Мінск 2003].

Bërk È., Filosofskoe issledovanie oproishoždenii naših idej vozvyšennogo i prekrasпоgo, Москва 1979 [Бёрк Э., Философское исследование о происхождении наших идей возвышенного и прекрасного, Москва 1979].

Vacuro V. 亡̀., Gotičeskij roman v Rossii, Moskva 2002 [Вацуро В. Э., Готический роман в России, Москва 2002].

Kazloǔ A., İ tady â pamër... [online], https://knihi.com/Anatol_Kazlou/I_tady_ja_ pamior.html\#1, [dostup: 26.01.2020] [Казлоў A., I тадь я памёр... [online], https://knihi.com/Anatol_Kazlou/I_tady_ja_pamior.html\#1, [доступ: 26.01. 2020]].

Kazloǔskì R., Gotyka ǔ tvorčasci Mikoly Kascûkeviča (na prykladze apavâdannâ «Lâl'ka», "Na Nëmanskaj hvalì" 2014, № 4 [Казлоўскі P., Готылка ў творчасиі Міколь Касиюкевіча (на прыкладзе апавядання «Лялька», "На Нёманскай хвалі" 2014, № 4].

Radcliffe A., On the supernatural in poetry, "New Monthly Magazine", 1826, Vol. 16, № 1 [Radcliffe A., On the supernatural in poetry, "New Monthly Magazine", 1826, Vol. 16, № 1].

\section{P E 3 Ю $\mathrm{E}$}

\section{ГОТИЧЕСКАЯ ЭСТЕТИКА В РАССКАЗЕ АНАТОЛИЯ КОЗЛОВА «І ТАДЫ Я ПАМЁР..."}

Готическая литература проявляет большой интерес к природе человеческого страха, его воздействию на психику, на душевные и духовные сферы деятельности личности. Интерес белорусских писателей к необъяснимым явлениям всегда присутствовал в национальной литературе, с новой силой он 
проявился в конце XX века. В творчестве А. Козлова выявилась склонность к мистификации, обилию фольклорных мотивов и образов, к философской рассудительности. Рассказ писателя «І тады я памёр...»- это глубокое размышление о смерти, смысле жизни, о предназначении человека и о таинственном потустороннем мире. Автор показал глубину переживаний личности, ее антропологическое одиночество. Готические элементы в произведении стали тем важным акцентом, который помог писателю актуализировать свое мировидение.

Ключевые слова: готическая литература, готическая эстетика, одиночество личности, белорусская литература, Анатолий Козлов.

\section{S T R E S Z C Z E N I E}

\section{ESTETYKA GOTYCKA W OPOWIADANIU ANATOLA KOZLOVA „I TADY JA PAMIOR...”}

Literaturę gotycką interesuje natura ludzkiego strachu i jej wpływ na psychikę, mentalne i duchowe sfery aktywności człowieka. Pisarze białoruscy od zawsze wykazywali zainteresowanie niewyjaśnionymi zjawiskami, które zintensyfikowało się w końcu XX wieku. Pisarz A. Kozlov stosuje szereg ludowych motywów i obrazów. W jego książkach obecny jest osąd filozoficzny. Opowiadanie „I tady ja pamior...” jest głebokim rozważaniem nad śmiercią, znaczeniem życia, przeznaczeniem człowieka i tajemniczością świata. Autor pokazuje głębiny ludzkiego doświadczenia, jego antropologiczną samotność. Elementy gotyckie obecne w opowiadaniu pomogły pisarzowi zaktualizować jego wizje świata.

Słowa kluczowe: literatura gotycka, estetyka gotycka, samotność jednostki, literatura białoruska, Anatol Kozlov.

\section{S U M M A R Y}

\section{GOTHIC AESTHETICS IN THE STORY BY ANATOLY KOZLOV "AND THEN I DIED..."}

Gothic literature is interested in the nature of human fear and its effects on the psyche, on the mental and spiritual sphere of individual activities. Belarusian writers have always shown interest to unexplained phenomena, and it has even become stronger in the late twentieth century. The writer A. Kozlov uses plenty of folk motifs and images. Philosophical judgment is present in his books. The story "And then I died ..." is a profound meditation on death, the meaning of life, the destiny of a man and mysterious world beyond. The author has shown the depth of experience of an individual, his anthropological solitude. Gothic elements in the story become an important focus that helped the writer to actualize his vision of the world.

Key words: gothic literature, gothic aesthetics, loneliness of an individual, Belarusian literature, Anatoly Kozlov. 